O BRAVE NEW PRINT COLLECIION, IHAT HAS SUCH DATA SCIENCE BOOKS IN II!

Heidi Tebbe, Collections \& Research Librarian for Engineering and Data Science, hjtebbe@ncsu.edu Mira Waller, Interim Department Head, Research Engagement, mpark@ncsu.edu

\section{WHEREAORE DATA}

The field of data science exists at the intersection of several disciplines, including statistics, social science, information science, computer science, and visualization. This can make collection development for data science challenging, but it's a field that has become increasingly important in industry and academia.

Data scientists, and increasingly researchers, academics, and others, work with large amounts of data, complex computation, and data visualization to solve real-world problems. Those working in or studying data science may need to learn new skills and tools to be successful.

North Carolina State University recognizes the importance of this growing field, as shown in the establishment of the Data Science Initiative (DSI); courses taught by faculty in computer science, statistics, advanced analytics, and management; and research conducted at interdisciplinary centers and institutes.

\section{E-PREAERRED (USUALIY)}

While NCSU Libraries prefer electronic books, this is a print collection. The collection was originally created for inclusion in a renovated physical location. We also get requests for print books in related subject areas such as statistics and mathematics. This collection can be used to showcase our support of data science and can help to reinforce the alignment of a particular space as a data hub.

\title{
THE COLLECTION
}

* 133 books on the initial list $\rightarrow 75$ books actually purchased

- The books span the collecting areas of 7 selectors and 16 subject fund codes

* Computing \& Electronics

* Language \& Linguistics

* General Science

- General Humanities \& Social Sciences

* Economics

* Library Science

* Statistics

* Business Management

* Education

* Mathematics

- Psychology

- Graphic \& Information Design

* Industrial Design

* General Technology

* Human Communication

* Physics

- The books can be roughly divided into four categories:

Visualization
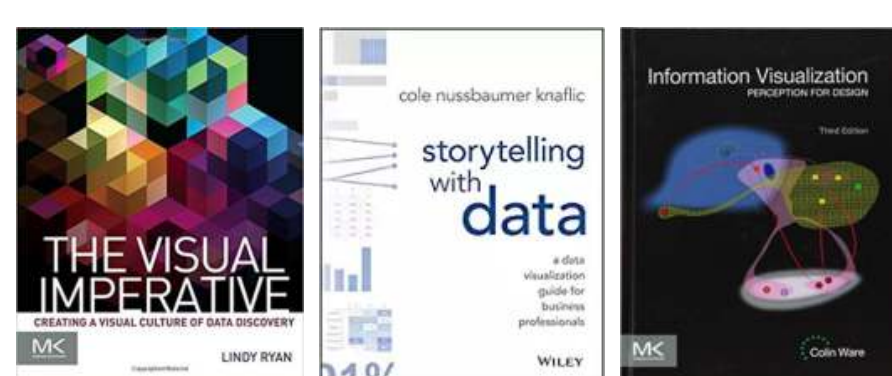

Programming
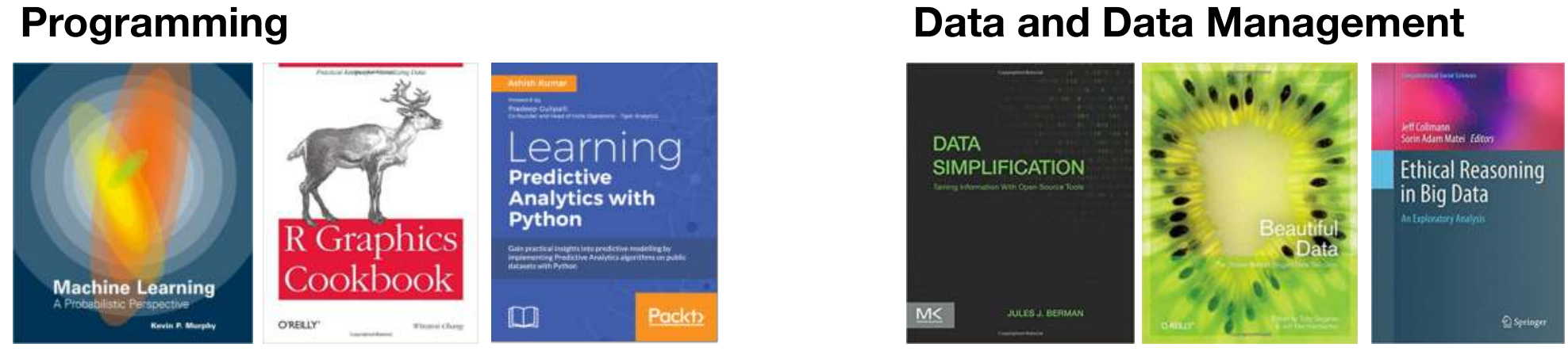

- Between June 2017 and October 2017, more than one-third of the newly purchased books had already been checked out at least once - Programming and Visualization have been the most popular categories so far

\section{OUR PROCESS}
1. Asked to create a data science print collection with an allocation of $\$ 5,000$
2. Determined broad criteria for the collection
3. Created an initial list of books
4. Removed books from the list that we already owned in print
5. Associated each book with an existing fund code
6. Sent list of books to Acquisitions \& Discovery for purchase
7. Added a unique identifier to catalog records in order to internally identify the collection

\section{FINDING THE BOOKS}

- Recommendations from NCSU librarians

* Websites about data science

- Lists on Amazon and Goodreads

* Syllabi for data science courses

and programs

* GOBI notification

* Existing fund codes were too

broad

* No interdisciplinary topic for data science in GOBI

Subject Headings Data mining; information visualization; big
data; visualization; data protection: datg data; visualization; data protection;
structures; distributed processing

keyword; multiple items accepted

\section{PRESENT AND TUTURE}

- Books have been purchased and added to circulating collection

- Renovation of the space hasn't happened yet, but books can be pulled at any time using the "DATASCl" identifier

- May inform a future data science fund and collecting efforts

- A new GOBI notification was created based on call numbers

- More analysis may be conducted about the use of the collection

的 NCSU LIBRARIES 